\title{
Microvascular Injury With Secondary Edema, Bronchoconstriction and Vasoconstriction of Non-involved Lung Parenchymal Segments May Contribute to Clinical Deterioration of Non-critically III Patients Hospitalized for SARS-CoV-2 Pneumonia Without Evidence of Pulmonary Embolism: A Preliminary Study.
}

\section{Cécile MAINCENT}

Centre Hospitalier Princesse Grace

Christophe PERRIN

Centre Hospitalier Princesse Grace

Gilles CHIRONI

Centre Hospitalier Princesse Grace

Marie Baqué-Juston

Centre Hospitalier Princesse Grace

Frédéric Berthier

Centre Hospitalier Princesse Grace

Benoit Paulmier

Centre Hospitalier Princesse Grace

Florent Hugonnet

Centre Hospitalier Princesse Grace

Claire Dittlot

Centre Hospitalier Princesse Grace

Ryan Lukas Farhad

Centre Hospitalier Princesse Grace

Julien Renvoise

Centre Hospitalier Princesse Grace

\section{Benjamin Serrano}

Centre Hospitalier Princesse Grace

Valérie Nataf

Centre Hospitalier Princesse Grace

François Mocquot

Centre Hospitalier Princesse Grace

Olivia Keita-Perse

Centre Hospitalier Princesse Grace

Yann-Erick Claessens

Centre Hospitalier Princesse Grace

Marc Faraggi ( $\square$ marc.faraggi@chpg.mc)

Centre Hospitalier Princesse Grace https://orcid.org/0000-0002-7233-1410

\section{Research Article}

Keywords: SARS-CoV-2 pneumonia, Pulmonary Embolism, Microvascular injury, Secondary Edema, Vasoconstriction, Bronchoconstriction 
DOI: https://doi.org/10.21203/rs.3.rs-710833/v1

License: @ (i) This work is licensed under a Creative Commons Attribution 4.0 International License. Read Full License 


\section{Abstract}

Purpose: We aimed to better understand the pathophysiology of SARS-CoV-2 pneumonia in non-critically ill hospitalized patients secondarily presenting with clinical deterioration and increase in oxygen requirement.

Methods: We consecutively enrolled patients without clinical or biological evidence for superinfection, without left ventricular (LV) dysfunction and for whom a pulmonary embolism was discarded by computed tomography pulmonary angiography. We investigated lung ventilation and perfusion (LVP) by LVP scintigraphy, and, 24 hours later, left and right ventricular function by ${ }^{99 \mathrm{~m}} \mathrm{Tc}$-labelled albumin gated-blood-pool scintigraphy with late $(60 \mathrm{mn})$ tomographic albumin images on the lungs to evaluate lung albumin retention that could indicate microvascular injuries with secondary edema.

Results: We included 13 patients with confirmed SARS-CoV-2 pneumonia. All had CT evidence of organizing pneumonia and normal LV ejection fraction.

No patient demonstrated preserved ventilation with perfusion defect (mismatch), which may eliminate a distal lung thrombosis. Patterns of ventilation and perfusion were heterogeneous with sometimes healthy lung segments paradoxically hypoperfused and hypoventilated while both normal perfusion and ventilation were maintained in segments with organizing pneumonia $(n=4)$. Lung albumin retention in area of organizing pneumonia was observed in 9 patients, indicating microvascular injuries, vessel permeability increase and secondary edema.

Conclusion: In hospitalized non-critically ill patients without pulmonary embolism or LV dysfunction, various types of damage may contribute to clinical deterioration including microvascular injuries and secondary edema, broncho and vasoconstriction of area not involved by organizing pneumonia while no evidence was found for significant distal thrombosis detectable by LVP scintigraphy.

\section{Introduction}

The causes for clinical deterioration and increase in oxygen requirement in hospitalized patients with SARS-CoV-2 pneumonia remain uncertain. The extent of lung involvement assessed by computed tomography (CT) has been reported as a prognostic factor, still many patients exhibit a moderate extent but require admission to an intensive care unit while others present a larger extent but remain clinically stable. On the other hand, some patients have a good tolerance of hypoxemia despite CT images suggestive of extended organizing pneumonia (« happy hypoxemic » patients) [1, 2].

In order to explain these puzzling discordances between clinical presentation and imaging, and particularly the occurrence of a progressive deterioration in respiratory condition, a wide use of CT pulmonary angiography (CTPA) has been proposed to possibly detect pulmonary embolism. However, whether or not SARS-CoV-2-related pneumonia significantly increases the risk of venous thromboembolism remains unclear [3, 4].

Other hypotheses have emerged, including a vasculitis/endothelitis and thrombo-inflammatory process $[5,6]$ potentially associated with local peripheral thrombosis undetected by conventional CTPA. This « vasculocentric " approach is consistent with the observation of arterial vessels enlargement at CT [7, 8] and the potential loss of hypoxemia-related vasoconstriction in infected tissues $[7,9]$. Furthermore, a loss of distal microvasculature and scars of intra-alveolar deposit of fluid, fibrin and hyaluran, disrupted alveolar capillaries with platelet-fibrin microthrombi were also reported in pathology series [10]. However, these autopsy findings that reported endothelitis and alveolitis were performed in ultimately ill SARS-CoV-2 pneumonia $[8,10]$ but it is unclear if these damages may also occur in non-critically ill patients. Furthermore, the reduction of distal microvasculature does not necessarily imply microvessel thrombosis, as the inflammatory process itself may explain the (micro) vasculature impairment and may lead to an increase of vessel permeability, interstitial edema, elevation of interstitial pressure and external compression of the vessels' lumen, finally resulting in a drop of oxygen transportation and arterial blood flow. To our knowledge, such an edema in non-critically ill patients has never been evidenced in vivo. Additionally, the attenuation of small blood vessels is not specific of SARS-CoV-2-related pneumonia and occurs in any community-acquired pneumonia [11, 12]. Indeed, studies of CTPA combined with artificial intelligence [11, 12] have shown a lessering of pulmonary micro-vessels (below $5 \mathrm{~mm}^{2}$ ) in patients with COVID-19 as well as in community-acquired pneumonia, this decrease being a prognostic factor for the risk of mechanical ventilation or death [11].

To better understand the complex relationships between alveolar ventilation, pulmonary vascularization and interstitial edema related to abnormal permeability, we prospectively investigated non-critically ill COVID-19 patients admitted for a sudden clinical deterioration, 
or suddenly worsening during hospitalization, without clinical evidence for left ventricular dysfunction or lung superinfection and for whom pulmonary embolism was discarded by CTPA. Lung ventilation/perfusion was evaluated by lung ventilation/perfusion scintigraphy (LVPS) and we used ${ }^{99 \mathrm{~m}}$ Tc-labelled albumin gated-blood-pool scintigraphy (GBPS) for evaluation of left and right systolic function and detection of interstitial edema related to abnormal capillar permeability.

\section{Methods}

\section{Patients}

Non-critically ill patients hospitalized in the COVID-19 Unit of the Centre Hospitalier Princesse Grace of Monaco 1/ presenting with a sudden clinical deterioration defined by a respiratory rate impairment and/or a rise of oxygen flow to reach a peripheral capillary oxygen saturation (SpO2) of more than $95 \%$ during at least 48 hours and $2 /$ for whom a diagnosis of pulmonary embolism was discarded by CTPA, were prospectively included.

COVID-19 was confirmed according to the WHO guidance [13] by a positive result of RT-PCR assay of nasal and pharyngeal swabs, peripheral pulmonary ground-glass opacities (GGO) or air-space consolidation on their chest CT scan at admission and common laboratory findings including lymphocytopenia, eosinopenia, significantly elevated markers of organ inflammation such as fibrinogen and C-reactive protein [14]. Patients could not be included if their medical condition was unstable or precluded a safe transfer to the nuclear medicine department, if they were under mechanical ventilation (either non-invasive or invasive), if they required critical care unit, or in case of a pregnancy. The institutional review board for human studies approved the protocol and a written consent was obtained from all patients. Personal protective equipment was available for the staff, and all measures to ensure strict infection prevention were observed according to established guidance [15].

\section{Chest CT and CTPA :}

Chest CT-scan was performed with blocked inspiration using an Aquilion ONE PRISM (Canon Medical Systems, Okinawa, Japan) and the following parameters: tube voltage of $120 \mathrm{kVp}$ and an automatic tube current modulation (SUREexposure ${ }^{\mathrm{R}}$ ), rotation time 0.5 seconds, pitch factor 0.81 . Axial reconstructions were performed with a matrix size $512 \times 512$ with a hard convolution kernel FC35, appropriate for lung exploration, with $1 \mathrm{~mm}$ slice thickness and $0.8 \mathrm{~mm}$ slice spacing. The same procedure was used after contrast agent administration with a hard convolution kernel « bodysharp » $1 \mathrm{~mm} / 0.8 \mathrm{~mm}$ and intravenous administration of Optiject 350 (Guerbet, Villepinte, France), $50 \mathrm{ml}$ at a flow of $4 \mathrm{ml} / \mathrm{s}$.

\section{LVPS :}

LVPS imaging was performed within 24hrs after CTPA, in accordance with the recommendations of the European Association of Nuclear Medicine $(16,17)$ using a large-field-of-view dual-head gamma-camera with a low-energy, all-purpose collimator (WEHR45) was used (Discovery NM/CT 870 CZT General Electric). Four hundred and ten MBq of Technegas (Cyclomedica Ltd, Waterdown, Ontario, Canada) were inhaled and ventilation tomography was performed thereafter. Then, while the patient was carefully maintained in the same supine position, $185 \mathrm{MBq}{ }^{99 \mathrm{~m}} \mathrm{Tc}$-macroaggegates ((Pulmocis; Curium, Paris, France) were slowly injected intravenously followed by the perfusion tomography $(18,19)$.

All acquisitions were performed with body contour in a 128×128 matrix, zoom 1 with 60 projections over 360 degrees. For the ventilation study, each step was of 20 s duration, and for the perfusion study, 15 s duration were used for each step. Reconstruction was performed using ordered subsets expectation maximization with 10 subsets and 2 iterations and the resolution recovery option.

A combined CT acquisition was performed at $120 \mathrm{kV}$ with the smart $\mathrm{mA}$ tube current modulation (Min $30 \mathrm{~mA} / \mathrm{Max} 120 \mathrm{~mA} / \mathrm{noise}$ index up to 20 ), rotating time $0.7 \mathrm{~s}$, a pitch of 1.375 and a matrix size $512 \times 512$. The slice thickness acquisition was $2.5 \mathrm{~mm} / 2.5 \mathrm{~mm}$ (collimation $=16 \times 1.25 \mathrm{~mm}$ ) and a post reconstruction with lung filter and $1.25 \mathrm{~mm} / 1.25 \mathrm{~mm}$ was done. The mean values were for CTDIvol = $5.1 \mathrm{mGy}$ and for DLP =191 mGy.cm.

The ventilation study was performed in a room specifically dedicated for this activity and reserved for COVID-19 patients at the end of the daily program and then room and materials were fully cleaned and sterilized according to the institutional procedures.

\section{${ }^{99 m}$ Tc-albumin GBPS :}


The day following LVPS, 740MBq of Tc99m labeled albumin (Vasculocis 10mg, CIS-BIO International, Gif sur Yvette, France), were intravenously administered.

Cardiac GBPS was then performed in best septal left anterior oblique (around $30^{\circ}$ ) and left profile according to the following parameters: $128 \times 128$ matrix, $5000 \mathrm{Kcts}, 16$ bin zoom x2. Left and right ejection fraction (LVEF, RVEF) were automatically computed using a dedicated software (XTERNA, Xelerix 3, General Electric).

45-60 min after IV administration, a non-gated tomographic acquisition over the lungs was performed, with the same parameters than for PS SPECT, resulting in a late albumin acquisition (Alb).

\section{Scintigraphic data management.}

\section{Visual analysis :}

According to the ventilation and perfusion pattern of the pulmonary segments, each patient was classified into 1-"normal" when LV and PS demonstrated a normal and homogenous uptake, 2-"abnormal and matched" when both LV and LP were similarly altered, 3-"regularly mismatched" in case of hypoperfusion but normal ventilation and 4-"reversely mismatched" in case of hypoventilation but normal perfusion.

Furthermore, perfusion and ventilation of COVID-19 involved area were compared to those of "normal" area to detect the presence or paradoxically hypoperfused and hypoventilated normal segments. For quantitative analysis, area with patent emphysema on CT were systematically excluded.

\section{Quantitative analysis :}

On the CT acquired with LVPS, a circular ROI of at least $1 \mathrm{~cm}^{3}$ was drawn over an area free of CT, perfusion and ventilation abnormalities, preferentially in the upper lobe if possible. This area was considered as a reference area and the average counts extracted from the perfusion, the ventilation and the late albumin (Alb) scans were computed, defining the reference LV, PV and Alb counts. A similar area was drawn on the three (if available) most significant COVID19 CT abnormalities (round glass opacities or organizing pneumonia) and the same measurements were computed for each tomographic acquisition. The highest value was retained, defining respectively the LV, PS and Alb pathological counts. An index of pathological uptake was then defined for each method as the ratio of the pathological counts over the corresponding reference counts, defining 3 indexes : ventilation index ( $\mathrm{VI})$, perfusion index $(\mathrm{PI})$ and albumin index (Al). In healthy patients, perfusion indexes obtained by $\mathrm{PI}$ and $\mathrm{Al}$ are very close but may differ in case of lung/perfusion heterogeneity from one area to another or according to the pathology involved. Based on a personal series of 10 patient presenting with cardiogenic pulmonary edema, free of pulmonary infection and investigated by LVPS and GBPS, an albumin retention was considered significant when the ratio Al/PI was equal or above 1.7 (mean value +2 standard deviation of the non-infected patients).

\section{Adjudication committee classification for patients'short-term clinical outcome:}

An expert panel was launched to adjudicate patients' short-term clinical outcome. The expert panel consisted of 3 physicians experienced in intensive care, pulmonology, and emergency medicine and involved in the management of COVID-19 patients. To adjudicate each case, the expert panel was blinded to the results of LVPS but had full access to medical records, focusing on the kinetics of monitoring, treatment (notably oxygen delivery), and biology from 3 days before to 4 days after LVPS. Patients' short-term clinical outcome during hospitalization was classified as follows: worsening, stability, or improvement.

\section{Statistical management:}

Categorical variables were collected as numbers ( $n$ ) and percentages (\%). Continuous variables were described as median and interquartile range (IQR).

Prognosis was evaluated using categorical variables: worsening or stability vs improvement in the 15 following days, delay to the recovery of a $95 \%$ or more SpO2 in ambient air below vs above 15 days, hospitalization duration below vs above 15 days.

The prognostic value of the extent of CT abnormalities, a RVEF below $v s$ above $50 \%$, a significant albumin uptake (AI/PI) above or equal to 1.7, and the presence and/or number of paradoxically hypoventilated and hypoperfused normal segments were evaluated by 
Fisher's exact test and Mann Whitney U test.

\section{Results}

\section{Patients}

Fourteen patients were prospectively included; one was secondarily excluded because symptom onset began 2 months ago and clinical deterioration retrospectively appeared to be related to left ventricular heart failure. Population characteristics (12 male, one female: patient \#5) are summarized in Table I. All patients were infected with the B 1.1.7 variant.

No patient received oxygen therapy before inclusion except patient \#2 who received long term oxygen therapy (2L/min) for chronic obstructive pulmonary disease.

Nine patients were included because they required an increase in oxygen delivery from baseline status, 2 because a pulmonary thrombosis was suspected because of sudden hypoxemia and D-dimer increase (patients \#6 and \#8), 2 because oxygen therapy could not be withdrawn despite a moderate and stable involvement at CT.

All patients received corticosteroids, anticoagulant therapy doses were prophylactic in 11 patients, and full intensity in 2 because of a past history of venous thrombo-embolism (patients \#9 and \#12). Only 2 patients received anti-IL6-R therapy (Tocilizumab, patients \#1 and \#3). No patient experienced any secondary bacterial infection. The extent of CT abnormalities ranged from 10 to $70 \%$.

The delay to recovery of a $95 \%$ or more SpO2 in ambient air was 15 days or less in 8 patients and 2 months or more for the remaining 5 patients. Six patients were hospitalized for more than 15 days. Biological data are summarized in Table II.

LVPS.

No patient demonstrated pulmonary segments or sub-segments with both preserved ventilation and hypoperfusion (mismatch) that could be suggestive of distal thrombosis.

Perfusion and ventilation patterns were very heterogeneous from one patient to another but also within a same patient, among whom different patterns coexisted.

Three patients had normal LVPS. Six patients had concordant hypoventilated and hypoperfused segments or sub-segments (match), 2 in the area of pre-existing emphysema, 5 in the area of COVID-19 involvement. One among the five latter patients and 5 other patients had a reverse mismatch (segments or subsegments hypoventilated but without any perfusion defect). The pattern of ventilation and perfusion was very heterogeneous in 4 patients, demonstrating paradoxical concordant segments with hypoperfusion and hypoventilation in areas visually free from COVID19-involvement whereas both perfusion and ventilation were preserved in COVID19involved segments. In one case, a peripheral halo of hyperperfusion surrounding the COVID-19 involvement was seen on LVPS (Fig. 1). Those 4 patients had no past history of asthma.

Among 260 segments, 17 had matched abnormalities, 11 had a reverse mismatch, 15 segments free from COVID 19-involvement had a paradoxical matched hypoperfusion and hypoventilation, and 217 were normally ventilated and perfused. Three patients had tracheobronchial tract uptake of Technegas ${ }^{\mathrm{R}}$.

\section{GBPS.}

Nine patients showed a significant late pulmonary uptake of albumin in at least one COVID-19 area (Table 2 and Fig. 2). The patient secondarily excluded because of heart failure also demonstrated a significant albumin uptake, suggesting that SARS-CoV-2pneumonia might have previously altered the capillary barrier.

All patients had a normal LVEF (above 55\%) while 7 had a decreased RVEF (below 50\%).

Among the parameters evaluated for prognosis and defined above in the statistical section, none were associated with the short term clinical outcome (all $p>0.10)$.

\section{Discussion}


Among non-critically ill patients with CT evidence of SARS-CoV-2-related organizing pneumonia, our study evidences 1 / the presence of lung albumin retention in some COVID-19-involved areas indicating microvascular injuries, vessel permeability increase and secondary edema, 2 / the absence of any ventilation/perfusion mismatch, which may eliminate distal thrombi and 3 / very heterogenous patterns of ventilation and perfusion abnormalities with sometimes healthy lung segments paradoxically hypoperfused and hypoventilated while both perfusion and ventilation were preserved in segments with organizing pneumonia.

The injection of microspheres upstream in an organ is a reference experimental method to measure downstream tissular blood flow. Usually, this method requires very well calibrated microspheres and a sampling of the target tissue. Perfusion scintigraphy uses less well calibrated ${ }^{99 \mathrm{~m}} \mathrm{Tc}$ labelled-albumin microspheres (around $50 \mu \mathrm{m}$ and always less than $100 \mu \mathrm{m}$ ) and the external detection with a gamma-camera is not as accurate as a tissue sampling. Nevertheless, for a clinical use, PS is considered the best method to detect small distal pulmonary embolism and its results can be considered as a surrogate of lung vascularization evaluation. LVPS has been previously used in SARS-CoV-2 pneumonia to discard pulmonary embolism when CTPA was not indicated [20, 21, 22] or to evidence tracheobronchitis [23]. Furthermore, in case of normal CTPA and typically abnormal LVPS (i.e area with preserved ventilation and perfusion defect), impairment of distal vasculature might be detected whatever the mechanism (very distal and small pulmonary embolism or local thrombosis). Another way to evaluate local pulmonary vasculature is to use an intravascular tracer that is not supposed to escape out of the vessel. Because of a high molecular weight (around $70000 \mathrm{da}$ ), ${ }^{99 \mathrm{~m}}$ Tc-labelled albumin fulfills this criterion. Therefore, it might be expected that the perfusion phase of LVPS and ${ }^{99 \mathrm{~m}} \mathrm{Tc}$-albumin exhibit concordant data about pulmonary arterial blood flow. In case of an enhanced uptake of albumin in COVID-19-involved areas compared to PS estimation of the blood flow, as evaluated by the Al/PI ratio, a leakage of albumin out of the pulmonary capillaries as a consequence of abnormal capillaries permeability and endothelial dysfunction could be strongly suggested, as it has been described both in acute respiratory distress syndrome (Herrero) and in genetically modified mice permanently expressing the human angiotensin converting enzyme 2 receptor (ACE2) and infected with SARS-CoV-2 [24]. These capillaries injuries, usually described in very severe clinical presentations might occur in moderate to mild COVID-19-patients (as ours) with a preserved good prognosis.

In several clinical and histopathological models of tissue inflammation, interstitial and peri-vascular edema impairs the functional vascularization and tissue oxygen delivery, whatever the amount of microvessels involved. Indeed, the oxygen delivery is driven by a facilitated diffusion mechanism (the combination of a concentration and a pression gradient), and what increases the interstitial pressure decreases the oxygen diffusion throughout the microvessel walls. In myocardial sarcoïdosis, rest myocardial perfusion abnormalities due to myocardial inflammation are common and improved by the use of vasodilators, at least in the early phase of the disease, before late fibrosis fixes the abnormalities [25]. In oncology, the increase in peripheral tumor vasculature leads to a poor functional efficacy in oxygen transportation because microvessels are immature and exhibit tight junction abnormalities, and plasma leakage induces an elevation of the interstitial pressure, resulting in central tumor necrosis. Furthermore, the use of antiangiogenics has been reported as reducing tumor hypoxia by suppressing these pathological vessels. In other words, although it is not surprising that the hypoxic status is very dependent on the inflammatory pulmonary phase of the disease, the extent of this inflammation, as evidenced by ${ }^{18} \mathrm{~F}_{\mathrm{FDG}}$ PET studies, does not summarize the prognosis [26] and the participation of microvessel-damage-related edema is probably an exacerbating factor that can be evidenced by ${ }^{99 \mathrm{~m}} \mathrm{Tc}$-labelled albumin. This perivascular edema raises questions about the interpretation of the enlarged vessels seen on CT. It has been suggested that these images were related to a persisting increase in vessel blood flow of COVID-19-involved area, but our data do not support this hypothesis and rather suggest that visually enlarged vessels are due to a wall and intertitial edema, reducing oxygen transportation.

However, even in the same patient, areas with CT consolidation may demonstrate albumin uptake or not. As the albumin diffusion flux throughout the injured vessels may be reduced when the interstitial pressure increases, this apparent discrepancy might be explained by the coexistence of lesions of different ages and/or evolutionary phase.

One intriguing finding is that some supposed normal areas (i.e. looking free of COVID-19 involvement at CT) appeared less perfused and less ventilated than COVID-19-related "healed" areas that appeared normally perfused. In LVPS, in the absence of pulmonary embolism, most of these latter segments should rather appear both hypoventilated and hypoperfused, which is consistent - with the filling of alveoli and alveolar ducts with fibrinous, spindle-shaped fibroblasts and myofibroblasts that later form granulation tissue seen in organizing pneumonia $[1,27]$ and/or COVID-19 [5] -and with the interstitial edema perturbating the microvasculature function. These "normally perfused" images are very different from the typical inflammatory peripheral halo around SARS-CoV-2 pneumonia areas described on dual-energy CT [7] and shown on Fig. 1 on which the hypervascularization affects the boundaries of these lesions and not the core of the CT consolidation area. 
Bronchial constriction out of pathological segments has been known from decades for pulmonary embolism [28, 29, 30]. In a pulmonary embolism, bronchoconstriction is mediated by hypocapnia induced by hyperpnea and tachypnea that can also be observed in SARS-CoV-2 pneumonia. Vasoconstriction might also be a secondary effect of the SARS-CoV-2 virus action, which targets the ACE2 receptor and then perturbates the local renin/angiotensin regulation [24,31]. At the beginning of viral invasion by SARS coV-2, it has been suggested that the initial hyperhemia associated with a loss of local hypoxic vasoconstriction induce alveolar damage, featuring edema or even haemorrhage [6, 24, 32, 33], leading to a right-to-left shunt effect. A reflex vascular and bronchial constriction out of these involved areas might increase the dead space, reduce the functional lung capacity, and impair the compensatory respiratory capacity thus contributing to worsen hypoxia. It must be emphasized that our patients did not demonstrate clinical or biological evidence of lung superinfection despite three of them had tracheobronchial tract uptake of Technegas ${ }^{R}$ that could suggest tracheobronchitis as previously reported $[23,34]$.

\section{Study limitation.}

In this preliminary prospective study, the limited size of our series with respect to the numerous and various patterns of lung edema, ventilation and perfusion abnormalities that we evidenced does not allow identification of a prognostic factor and further studies must be driven to assess this point. Nevertheless, in our pathophysiologic purpose, we deliberately chose to enrol very selected patients, with the fewest confounding factors (i.e.pulmonary embolism, LV failure ..). Then the heterogeneous patterns we observed are probably representative of the multifactorial impact of SARS-CoV-2 on lungs of non-critically ill patients and emphasize the polymorphism of the symptoms resulting from different mechanisms at different stages of evolution. Even if the size of this series does not allow us to definitively conclude, the absence of evidence for distal arterial thrombosis raise the question about the appropriate management of preventive anticoagulation.

\section{Conclusion}

In a limited series of non-critically ill patients hospitalized for COVID-19 presenting with an increase in oxygen requirement and without any evidence for pulmonary artery embolism, LV dysfunction or lung superinfection, we investigated the relationship between ventilation, perfusion and damage of the alveolar-epithelial barrier as assessed by albumin retention. We observed a large heterogeneity of ventilation, perfusion and microvasculature impairments, among the CT lesions evocating an organizing pneumonia, even within the same patient but without evidence of distal thrombosis. Albumin retention suggesting microvasculature/alveolarepithelial barrier impairment and strong arguments for paradoxical bronchoconstriction and vasoconstriction of area that do not present parenchymal consolidation have been observed and may represent a significant worsening factor of baseline respiratory affliction.

\section{Declarations}

Funding : Not applicable

Conflicts of interest/Competing interests : None

Availability of data and material : all data are available on request

Code availability Not applicable

Ethics approval, consent to participate and for publication : The institutional review board for human studies approved the protocol and a written consent was obtained from the subjects

\section{References}

1. Kory P, Kanne JP. SARS-CoV-2 organising pneumonia: 'Has there been a widespread failure to identify and treat this prevalent condition in COVID-19?' BMJ Open Resp Res 2020; 7: e000724. doi:10.1136/ bmjresp-2020-000724.

2. Tobin MJ, Laghi F, Jubran A. Why COVID-19 silent hypoxemia is baffling to physicians. Am J Respir Crit Care Med. 2020;202:35660.

3. Roubinian NH, Dusendang JR, Mark DG, et al. Incidence of 30-Day Venous Thromboembolism in Adults Tested for SARS-CoV-2 Infection in an Integrated Health Care System in Northern California. JAMA Intern Med. 2021. 
doi:10.1001/jamainternmed.2021.0488.

4. Jimenez D, Garcia-Sanchez A, Rali P, et al. Incidence of VTE and Bleeding Among Hospitalized Patients With Coronavirus Disease 2019: A Systematic Review and Meta-analysis. Chest. 2021 Mar;159(3):1182-96. doi:10.1016/j.chest.2020.11.005.

5. Afshar-Oromieh A, Prosch H, Scahefer-Prokop C, et al. A comprehensive review of imaging findings in COVID-19 - status in early 2021. Eur J Nucl Med Mol Imaging. 2021 Jul;48(8):2500-24.

6. Sadegh Beigee F, Pourabdollah Toutkaboni M, Khalili N, et al. Diffuse alveolar damage and thrombotic microangiopathy are the main histopathological findings in lung tissue biopsy samples of COVID-19 patients. Pathol Res Pract 2020; 216 : 153228.

7. Lang M. Som A, Mendoza DP, et al. Hypoxaemia related to COVID-19: vascular and perfusion abnormalities on dual-energy CT. Lancet Infect Dis 2020, April 30, 2020. https://doi.org/10.1016/ S1473-3099(20)30367-4.

8. Osuchowski MF. Winkler MS, Skirecki T, et al. The COVID-19 puzzle: deciphering pathophysiology and phenotypes of a new disease entity. The Lancet Respir Med 2021 Jun,9(6): 622-42.

9. Varga Z, Flammer AJ, Steiger P, et al. Endothelial cell infection and endotheliitis in COVID-19. Lancet. 2020;395:1417-18.

10. Carsana L, Sonzogni A, Nasr A, et al. Pulmonary post-mortem findings in a series of COVID-19 cases from northern Italy: a twocentre descriptive study. Lancet Infect Dis. 2020;20:1135-40.

11. Morris MF, Pershad Y, Kang P, et al. Altered pulmonary blood volume distribution as a biomarker for predicting outcomes in COVID19 disease. Eur Respir J. Mar 2021; 2004133. [doi:10.1183/13993003.04133-2020].

12. George PM, Desai SR. COVID-19 pneumonia and the pulmonary vasculature - a marriage made in hell. Eur Respir J. 2021. [https://doi.org/10.1183/13993003.00811-2021]. in press.

13. WHO. Clinical management of severe acute respiratory infection when novel coronavirus (nCoV) infection is suspected: interim guidance, 2020. Published January 25, 2020. Date last updated: Mar 20, 2020. Date last accessed: Jun 15,2021. https://apps.who.int/iris/handle/10665/330854.

14. Maincent C. Berthier F, Fahrad RL, et al. Accuracy of routine biomarkers and blood leucocytes count to assist diagnosis of COVID19-associated pneumonia in adult patients visiting the emergency department. Research Square, 2021. [https://doi.org/10.21203/rs.3.rs-34817/v1].

15. Paez D, Gnanasegaran G, Fanti S, et al. COVID-19 pandemic: guidance for nuclear medicine departments. Eur J Nucl Med Mol Imaging. 2020;47:1615-9. [https://doi.org/10.1007/s00259-020-04825-8].

16. Bajc M, Neilly JB, Miniati M, et al. EANM guidelines for ventilation/perfusion scintigraphy: Part 1. Pulmonary imaging with ventilation/perfusion single photon emission tomography. Eur J Nucl Med Mol Imaging. 2009;36(8):1356-70. [https://doi.org/10.1007/s00259-009-1170-5].

17. Bajc M, Neilly JB, Miniati M, et al. EANM guidelines for ventilation/perfusion scintigraphy: Part 2. Algorithms and clinical considerations for diagnosis of pulmonary emboli with V/P(SPECT) and MDCT. nd MDCT. Eur J Nucl Med Mol Imaging. 2009;36(9):1528-38. [https://doi.org/10.1007/s00259-0091169-y].

18. Bajc M, Chen Y, Wang J, et al. Identifying the heterogeneity of COPD by V/P SPECT: a new tool for improving the diagnosis of parenchymal defects and grading the severity of small airways disease. International Journal of COPD. 2017;12:1579-87.

19. Jogi J, Jonson B, Ekberg M, et al. Ventilation-perfusion SPECT with 99mTc-DTPA versus technegas: a head-to-head study in obstructive and nonobstructive disease. J Nucl Med. 2010;51(5):735-41.

20. Dhawan RT, Gopalan D, Howard L, et al. Beyond the clot: perfusion imaging of the pulmonary vasculature after COVID-19. Lancet Respir Med. 2021 Jan;9(1):107-16.

21. Cobes N, Guernou M, David Lussato D, et al. Ventilation/perfusion SPECT/CT findings in different lung lesions associated with COVID-19: a case series. Eur J Nucl Med Mol Imaging. 2020 Sep;47(10):2453-60.

22. Zuckier LS. To everything there is a season: taxonomy of approaches to the performance of lung scintigraphy in the era of COVID19. Eur J Nucl Med Mol Imaging. 2021;48:666-66.

23. Bahloul A, Verger A, Mandry D, et al. Signs of tracheobronchitis may constitute the principal finding on the lung SPECT/CT images of COVID-19 patients. Eur J Nucl Med Mol Imaging. 2021 Jul;48(8):2525-30. doi:10.1007/s00259-020-05139-5.

24. Arcel VM, Costoya JA. SARS-CoV-2 infection in K18-ACE2 transgenic mice replicates human pulmonary disease in COVID-19. Cell Mol Immunol. 2021;18:513-4. [https://doi.org/10.1038/s41423-020-00616-1].

25. Le Guludec D, Menad F, Faraggi M, et al. Myocardial sarcoidosis. Clinical value of technetium-99m sestamibi tomoscintigraphy. Chest 1994 Dec; 106(6): 1675-82. [doi: 10.1378/chest.106.6.1675].

Page 9/14 
26. Dietz M, Chironi G, Claessens YE, et al. Covid-19 pneumonia: relationship between inflammation assessed by whole-body FDG PET/CT and short-term clinical outcome. Eur J Nucl Med Mol Imaging. 2021 Jan;48(1):260-8.

27. Fu F, Lou J, Xi D, et al. Chest computed tomography findings of coronavirus disease 2019 (COVID-19) pneumonia. Eur Radiol. 2020;Oct; 30(10):5489-98.

28. Gurewich V, Thomas D, Stein M, et al. Bronchoconstriction in the presence of Pulmonary Embolism. Circulation. 1963;27:339-45. [https://doi.org/10.1161/01.CIR.27.3.339].

29. Giuntini C. Ventilation/perfusion scan and dead space in pulmonary embolism: are they useful for the diagnosis? Q J Nucl Med 2001 Dec; 45(4): 281-6. [PMID: 11893964].

30. Fernandes CJ, Luppino Assad A-P, Alves-Jr JA, et al. Pulmonary Embolism and Gas Exchange. Respiration. 2019;98:253-62.

31. Lei Y, Zhang J, Schiavon CR, et al. SARS-CoV-2 Spike Protein Impairs Endothelial Function via Downregulation of ACE 2. Circulation Research. 2021;128:1323-6. [DOI: 10.1161/CIRCRESAHA.121.318902].

32. Herrero R, Sanchez G, Lorente JA. New insights into the mechanisms of pulmonary edema in acute lung injury. Ann Transl Med. 2018;6(2):32.

33. Ackermann M, Verleden SE, Kuehnel M, et al. Pulmonary vascular endothelialitis, thrombosis, and angiogenesis in Covid-19. N Engl J Med 2020; 383: 120-28.

34. Verger A, Bahloul A, Melki S, Karcher G, Imbert L, Marie PY. Tracheobronchitis signs observed on ventilation lung scintigraphy during the course of COVID-19 infection. Eur J Nucl Med Mol Imaging. 2020 Oct;47(11):2709-2710. doi: 10.1007/s00259-02004834-7.

\section{Tables}

\section{Table I: Patients clinical characteristics.}




\begin{tabular}{|c|c|c|c|c|c|c|c|c|c|}
\hline $\begin{array}{l}\text { Patient } \\
\#\end{array}$ & $\begin{array}{l}\text { Age } \\
\text { (y) }\end{array}$ & $\begin{array}{l}\text { Delay to } \\
\text { clinical } \\
\text { deterioration } \\
\text { since } \\
\text { symptom } \\
\text { onset (d) }\end{array}$ & $\begin{array}{l}\text { Respiratory } \\
\text { rate (/min) }\end{array}$ & $\begin{array}{l}\text { Increment } \\
\text { in } 02 \\
(1 / \mathrm{min})\end{array}$ & $\begin{array}{l}\text { Hospitalization } \\
\text { duration (d) }\end{array}$ & $\begin{array}{l}\text { Extent of } \\
\text { COVID } \\
\text { involvement } \\
\text { at baseline } \\
\text { CT (\%) }\end{array}$ & $\begin{array}{l}\text { Co- } \\
\text { morbidity }\end{array}$ & $\begin{array}{l}\text { Delay to } \\
95 \% \\
\text { Sp02 } \\
\text { recovery } \\
\text { (d) / } \\
\text { residual } \\
\text { O2 } \\
\text { therapy } \\
\text { (1/min) }\end{array}$ & $\begin{array}{l}\text { Clinical } \\
\text { evolution }\end{array}$ \\
\hline 1 & 77 & 12 & 24 & 6 & 32 & 20 & HT, FA & $>60 / 1$ & W (ICU) \\
\hline 2 & 80 & 10 & 16 & 7 & 28 & 10 & $\begin{array}{l}\text { COPD, } \\
\text { CAD, RD, } \\
\text { HT }\end{array}$ & $60 / 0$ & $S$ \\
\hline 3 & 54 & 24 & 16 & 5 & 20 & 70 & BMI, HT & $>60 / 1$ & I \\
\hline 4 & 87 & 15 & 22 & 5 & 45 & 40 & CAD & $60 / 0$ & $S$ \\
\hline 5 & 61 & 13 & 21 & 1 & 8 & 20 & HT & $4 / 0$ & I \\
\hline 6 & 68 & 15 & 20 & 5 & 16 & 30 & BMI & $13 / 0$ & $S$ \\
\hline 7 & 85 & 9 & 28 & 6 & 16 & 40 & $\begin{array}{l}\text { HT, BMI, } \\
\text { DM }\end{array}$ & $>60 / 1$ & I \\
\hline 8 & 79 & 10 & 16 & 2 & 6 & 15 & $\begin{array}{l}\text { DM, AF, } \\
\text { HT, CAD }\end{array}$ & $4 / 0$ & I \\
\hline 9 & 61 & 14 & 22 & 4 & 10 & 25 & 0 & $10 / 0$ & I \\
\hline 10 & 52 & 10 & 24 & 5 & 10 & 20 & 0 & $9 / 0$ & I \\
\hline 11 & 86 & 15 & 12 & 4 & 10 & 60 & HT & $9 / 0$ & I \\
\hline 12 & 40 & 10 & 22 & 5 & 10 & 60 & BMI, Asth & $9 / 0$ & I \\
\hline 13 & 54 & 12 & 20 & 1 & 5 & 10 & $\begin{array}{l}\text { BMl, } \\
\text { CAD, } \\
\text { Asth }\end{array}$ & $3 / 0$ & I \\
\hline Median* & 68 & 12 & 21 & 5 & 10 & 25 & & & $\begin{array}{l}\text { WP : } 4 \\
(31 \%)\end{array}$ \\
\hline IQR* & 26 & 5 & 6 & 1 & 10 & 20 & & & $\begin{array}{l}1: 9 \\
(69 \%)\end{array}$ \\
\hline
\end{tabular}

$\mathrm{CT}=$ Computed Tomography, $\mathrm{W}=$ Worsening, $\mathrm{ICU}=$ intensive Care Unit, I= Improvement, $\mathrm{S}=$ Stability, $\mathrm{HT}=$ Hypertension, $\mathrm{AF}=\mathrm{Atrial}$ Fibrillation, $\mathrm{BMI}=$ Body Mass Index $>30, \mathrm{DM}=$ Diabetes Mellitus, Asth= asthma, $\mathrm{CAD}=$ Coronary Artery Disease, $\mathrm{COPD}=\mathrm{Chronic}$ Obstructive Pulmonary Disease, RD = Renal Dysfunction, $0=$ none, IQR = Interquartile Range, * Median / IQR or number and percentage if appropriate.

Table 2. Patients biological and scintigraphic data. 


\begin{tabular}{|c|c|c|c|c|c|c|c|c|c|c|}
\hline $\begin{array}{l}\text { Patient } \\
\#\end{array}$ & $\begin{array}{l}\text { CRP } \\
(\mathrm{mg} / \mathrm{L})\end{array}$ & $\begin{array}{l}\text { Fibrinogen } \\
(\mathrm{g} / \mathrm{L})\end{array}$ & $\begin{array}{l}\text { D-dimer } \\
\text { (mg/L) }\end{array}$ & $\begin{array}{l}\text { Leucocytes } \\
(/ \mu \mathrm{L})\end{array}$ & $\begin{array}{l}\text { Procalcitonin } \\
\text { (mg/L) }\end{array}$ & $\begin{array}{l}\text { LVEF } \\
\text { (\%) }\end{array}$ & $\begin{array}{l}\text { RVEF } \\
\text { (\%) }\end{array}$ & $\begin{array}{l}\text { Scintigraphic } \\
\text { pattern } \\
\text { (number of } \\
\text { segments) }\end{array}$ & $\mathrm{Al} / \mathrm{PI}$ & $\begin{array}{l}\text { Albumin } \\
\text { uptake }\end{array}$ \\
\hline 1 & 45.6 & 4.67 & 228 & 8.32 & 0.13 & 59 & 40 & $\begin{array}{l}\text { M (1), RMI } \\
(1), P M N ~(0) \\
\text { N(18) }\end{array}$ & 2.9 & + \\
\hline 2 & 93.2 & 7.29 & 2007 & 5.51 & 0.78 & 75 & 71 & $\begin{array}{l}\text { M (7), RMI } \\
(2), P M N ~(3), \\
\text { N(8) }\end{array}$ & 1.9 & + \\
\hline 3 & 0.6 & 2.26 & 437 & 6.68 & 0.03 & 58 & 55 & $\begin{array}{l}\mathrm{M}(2), \mathrm{RMI} \\
(0), \mathrm{PMN}(0) \\
\mathrm{N}(18)\end{array}$ & 2.3 & + \\
\hline 4 & 75.3 & 4.34 & 6758 & 6.89 & 0.15 & 60 & 55 & $\begin{array}{l}\mathrm{M}(0), \mathrm{RMI} \\
(0), \mathrm{PMN}(0) \\
\mathrm{N}(20)\end{array}$ & 1.5 & - \\
\hline 5 & 8.2 & 3.60 & 762 & 4.72 & 0.10 & 72 & 45 & $\begin{array}{l}\text { M (2), RMI } \\
(0), P M N(0) \\
\text { N(18) }\end{array}$ & 14.4 & + \\
\hline 6 & 26.3 & 4.53 & 782 & 10.63 & 0.06 & 64 & 60 & $\begin{array}{l}\mathrm{M}(0), \mathrm{RMI} \\
(5), \mathrm{PMN}(0) \\
\mathrm{N}(15)\end{array}$ & 1.8 & + \\
\hline 7 & 178.0 & 6.08 & 4360 & 6.39 & 0.17 & 59 & 67 & $\begin{array}{l}\text { M (1), RMI } \\
(0), P M N ~(7), \\
\text { N(12) }\end{array}$ & 1.3 & - \\
\hline 8 & 41.5 & 4.74 & 1511 & 3.46 & 0.11 & 56 & 39 & $\begin{array}{l}\text { M (0), RMI } \\
(0), P M N(0) \\
\text { N(20) }\end{array}$ & 2.3 & + \\
\hline 9 & 6.2 & 4.29 & 785 & 8.70 & 0.05 & 62 & 36 & $\begin{array}{l}\text { M (0), RMI } \\
(0), P M N ~(2), \\
\text { N(18) }\end{array}$ & 1.7 & + \\
\hline 10 & 19.0 & 3.50 & 1288 & 8.84 & 0.06 & 58 & 49 & $\begin{array}{l}\mathrm{M}(0), \mathrm{RMI} \\
(0), \mathrm{PMN}(0) \\
\mathrm{N}(20)\end{array}$ & 1.5 & - \\
\hline 11 & 20.9 & 3.64 & 655 & 9.09 & 0.07 & 63 & 49 & $\begin{array}{l}\text { M (2), RMI } \\
(0), P M N ~(3) \\
\text { N(15) }\end{array}$ & 1.5 & - \\
\hline 12 & 118.0 & 6.88 & 509 & 4.29 & 0.12 & 60 & 43 & $\begin{array}{l}\text { M (1), RMI } \\
(3), P M N(0) \\
\text { N(16) }\end{array}$ & 1.7 & + \\
\hline 13 & 1.7 & 3.51 & 215 & 7.73 & 0.04 & 65 & 64 & $\begin{array}{l}\text { M (1), RMI } \\
(0), P M N ~(0) \\
\text { N(19) }\end{array}$ & 1.8 & + \\
\hline$\underset{\star}{\text { Median }}$ & 26.3 & 4.30 & 782 & 6.89 & 0.10 & 60 & 49 & & 1.8 & $\begin{array}{l}+: 9 \\
(69 \%)\end{array}$ \\
\hline IQR & 67.1 & 1.14 & 1002 & 3.19 & 0.07 & 5 & 17 & & 0.8 & $\begin{array}{l}-:: 4 \\
(31 \%)\end{array}$ \\
\hline
\end{tabular}

$\mathrm{CRP}=\mathrm{C}$-Reactive Protein. LVEF = Left Ventricular Ejection Fraction, RVEF = Right Ventricular Ejection Fraction, M= match (segments with concordant altered perfusion and ventilation), RMI= reverse mismatch (hypoventilated segments with preserved perfusion), PMN : paradoxically matched (hypoperfused and hypoventilated normal segments), $\mathrm{N}=$ Normally perfused and ventilated segments. Al/PI : Albumin Index/ Perfusion Index. IQR = Interquartile Range, * Median / IQR or number and percentage if appropriate.

\section{Figures}



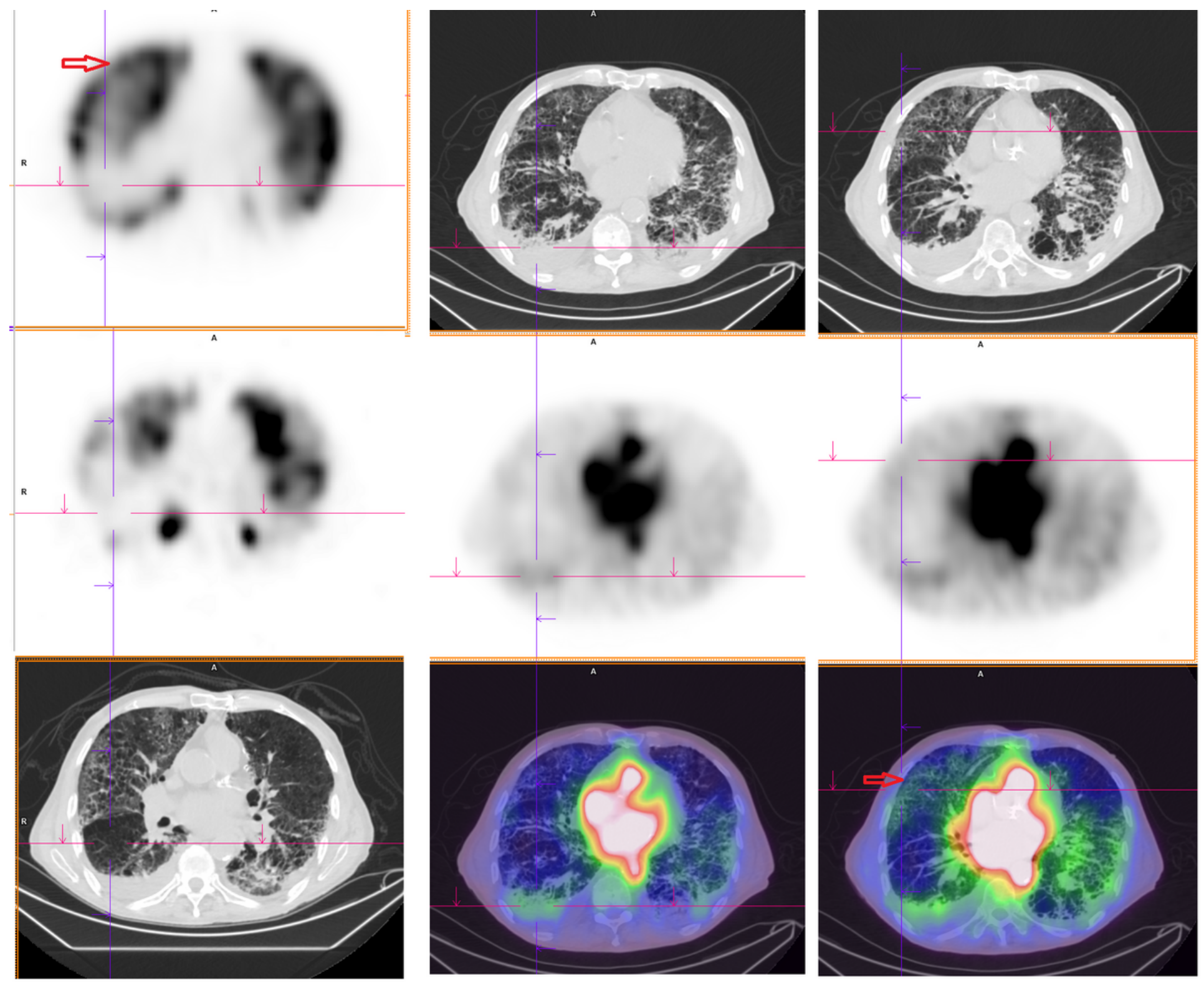

\section{Figure 1}

Patient \#2. Left row : From top to bottom, perfusion scan, ventilation scan, CT scan. The blue/red cross indicates a non COVID19involved area of the right Fowler lobe, with paradoxically matched hypoperfusion and hypoventilation while the COVID19-involved area of the right superior lobe just in front is normally perfused with a slightly hyperperfused peripheral halo (red arrow). Middle row : From top to bottom, CT scan, albumin scan and CT+albumin fusion scan. COVID19 condensation of the right base (blue/red cross) with significant albumin uptake and moderate pleural effusion behind. There is also a moderate albumin uptake of the left inferior lobe. Right row : From top to bottom, CT scan, albumin scan and CT+albumin fusion scan. The moderate albumin uptake in the area of the peripheral halo of the COVID19-involved area in the right superior lobe (red arrow) is related to the corresponding hyperperfusion. 

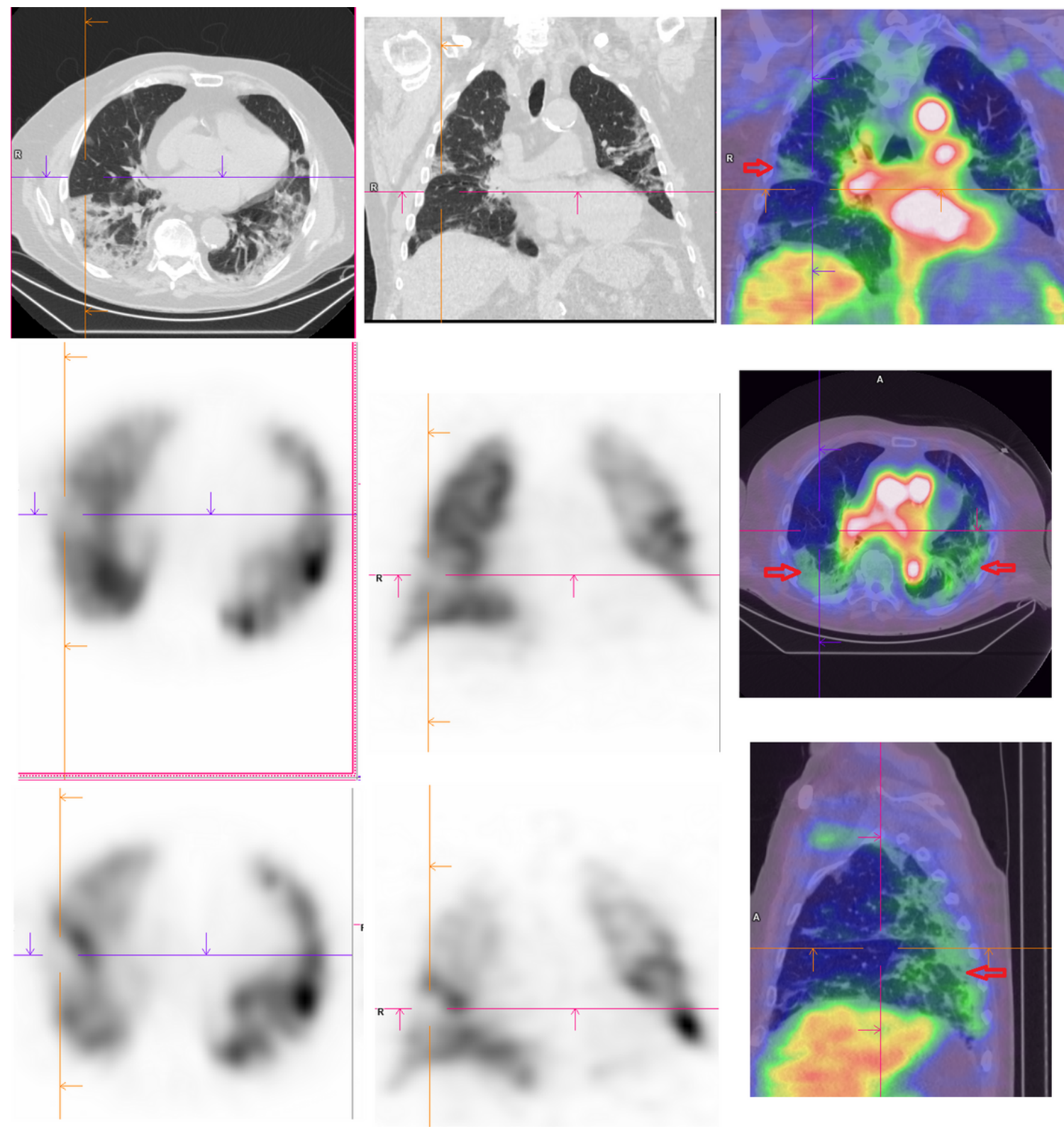

\section{Figure 2}

Patient \#7. Left row : From top to bottom, CT scan, perfusion and ventilation axial slices. The blue/red cross indicates a non COVID19involved sub-segment of the right inferior lobe, with paradoxically matched hypoperfusion and hypoventilation while the COVID19involved area just behind is normally ventilated and perfused. Middle row : From top to bottom, CT scan, perfusion and ventilation coronal slices. Right row : From top to bottom, fused CT and albumin scan : coronal, axial and sagittal slices of the same area. The condensed area related to COVID19 involvement just above and behind the COVID19-free area demonstrate a significant albumin uptake (displayed in green) that is also present in the left inferior lobe (red arrow). 